\title{
Using the Delphi method to develop the social-ecological resilience indicators of organic rice production in Thailand
}

\author{
Chaiteera Panpakdee ${ }^{1} \oplus$, Suchint Simaraks ${ }^{1}$, and Chanidapa Sookcharoen ${ }^{2, *}$
}

\author{
AFILIATIONS \\ 1. Department of Agricultural \\ Extension and System \\ Approaches, Faculty of \\ Agriculture, Khon Kaen \\ University, Khon Kaen, \\ Thailand \\ 2. International College, Khon \\ Kaen University, Khon Kaen, \\ Thailand \\ * Correspondence: \\ chanid@kku.ac.th
}

RECEIVED 2021-07-29

ACCEPTED 2021-12-31

COPYRIGHT () 2022 by Forest and Society. This work is licensed under a Creative Commons Attribution 4.0 International License

\begin{abstract}
This paper illustrates the application of the Delphi method, which assists in the production of social-ecological resilience indicators, and which are suitable for building the resilience of organic rice production in the central portion of Northeastern Thailand. Forty-seven adept farmers were purposively selected as participants, and the Delphi method was utilized as a tool by which the participants could reveal their different opinions and ideas. They were surveyed in order to visualize an organic rice system called the 'desirable system.' Nevertheless, such a system must be built simultaneously with certain components, the attributes of which can enable the system to withstand all kinds of change that can take place across spatial and temporal scales. The resilience literature, which is related to agro-ecological systems, had been published online during the seven previous years, and was applied to formulate questions, which were specifically aimed at establishing components that were focused upon coping and adaptive strategies. It was discovered that the inclusion of a group discussion, which had taken place with two rounds of the Delphi method, had provided a valuable means for exchanging information and responding with feedback. Given that the processes had been entirely conducted through group discussions, the voices of a few participants were, however, lost. They were dominated by the innate power expressed by other members within the group, especially the leaders. Despite this, the Delphi method was able to achieve an adequate degree of consensus among participants and was able to lead in the direction of building resilience with a significant level of confidence, which was capable of overcoming the social-ecological complexities of organic rice production. This was evidenced by the discovery of 21 social-ecological resilience indicators, which had been constructed by the engagement. Moreover, the indicators had indeed been reliable. With the support of the consensus of the participants' judgements, which were based on their actual contexts of organic rice production in the central portion of Northeastern Thailand, the indicators were able to be validated by statistical analyses, consisting of arithmetic means (x), standard deviations (sd), and interquartile ranges $(R)$.
\end{abstract}

\section{KEYWORDS}

Delphi; Participatory approach; Social-ecological resilience; Resilience indicator; Developing indicator

\section{INTRODUCTION}

The term, resilience was first defined by C.S. Holling in 1973 as the amount of disturbance that ecological systems can absorb all kinds of unexpected changes to sustain their original domain of the function, operations, and mechanisms for helping stakeholders to better understand the non-linear dynamics that exist between human activities and ecosystems (Allen et al., 2014; Folke et al., 2021). Since then, it has been predominantly utilized in academic fields, ranging from the agricultural and environmental sciences to the medical sciences (Ciftcioglu, 2017). It proposes a superior opportunity to achieve sustainable development because every uncertainty is 
considered to be a blessing owing to the fact that it provides lessons, which can be explored by trial and error, and which can target the establishment of effective adaptability and transformability across temporal and spatial scales (Choundhury et al., 2021). Therefore, the concept of resilience is practicable. It is a feasible solution to the problem of discovering how things change dynamically, which cannot be effectively administered by the paradigm of command and control like sustainable development (Imperiale \& Vanclay, 2019).

However, accomplishing adaptability and transformability can't come from nowhere, but instead, require four imperative features, which are relevant to building resilience (Folke, 2016). Firstly, there is learning to live with change and uncertainty. This feature focuses on how to gain advantages from having knowledge that has been advocated by learning and from gaining experience and thereby, transforming those disturbances into opportunities that are in tune with the biosphere (Folke et al., 2021). Secondly, there is the act of nurturing diversity for reorganization and renewal, which emphasizes the significance of nurturing various forms of diversity in order that individuals can cope with unforeseen surprises. The abundance of diversity should not only be seen as insurance against volatility, but can be viewed as history and me mory, which are embedded in the social-ecological system, and which are available to establish creative development following a crisis (Samaraweera, 2020). Thirdly, combining different types of knowledge for learning is the feature that focuses on the importance of peoples' knowledge, experiences, and their awareness of ecosystem dynamics, as well as their inclusion in management practices and institutions (Tittonell, 2020). Finally, the creation of opportunities for self-organization has also been cited as being vital for every resilient system (Panpakdee, 2018). The last draws together all of the key features of resilience within the context of self-organization. Moreover, external drivers emphasize the importance of the dynamic interplay between diversity and interference (Caldwell, 2015).

As previously mentioned, it is apparent that building the resilience of systems is arduous, especially when the systems have various components and have stakeholders, who need to be considered. As noted in the literature, agriculture is one of the systems that is shaped by reason (Panpakdee \& Palinthorn, 2021). Firstly, agriculture is complicated because it contains non-linear interactions that take place between biophysical, ecological, climatic, and social influences, as well as to varying degrees, economic and political influences (FAO, 2012). Secondly, since agriculture is primarily a physical activity, there has inevitably been a tendency to concentrate on it quantitatively, rather than qualitatively (ACT, 2020). Many factors, such as labor, the environment, and supply \& demand in the market, are all are responsible for high yields and are regularly adjusted to meet the needs of the consumers (NESDC, 2019). Thirdly, agriculture itself is instituted by the existing components and linkages between farmers and social-ecological systems (i.e., geology, climate, soil quality, pests, and diseases), which support the viability of each other. In other words, when a farmer desires to carry out an agricultural activity, other systems are required to manipulate related policies, such as regulations, finances, and marketing, which include the necessary infrastructure to reach an appropriate degree of yield (Panpakdee \& Palinthorn, 2021). In brief, these constructs imply that building resilience in agriculture is complicated. Not only does this system have multiple components to be concerned with, but there are also some components, which are dynamic and others, which are for reasons, prone to unpredictability (Samaraweera, 2020). For example, sufficient agricultural water, 
which is contributed by rainfall, is required to achieve an efficient level of productivity. However, no one can manipulate an abundance of rainfall throughout a growing season because it is not determined by human efforts, but by hydro-meteorological factors (Amare et al., 2018). Thus, the circumstances require the presence of goals, practices, and measurements, which are defined by the stakeholders and are designed to build resilience in order to be the least susceptible when needing to cope with impromptu changes (Choundhury et al., 2021).

As recommended by Uday and Marais (2014), a preliminary step in building the resilience of all systems is to develop a specific set of indicators. In brief, the indices are called resilience indicators in most of the literature and are considered to be both qualitative and quantitative tools (Panpakdee, 2018). They are developed by aggregating a system's vital components, which are associated with the approaches of building resilience in order to strengthen the robust operation of a system, and allowing it to cope with the unknown, with uncertainty, and with surprises (Van Oudenhoven et al., 2010). Therefore, the existence of these indicators is crucial. Similar to the conventional indices, they are utilized as a monitoring tool to quantify the resilience of a system (Quinlan et al., 2015). Moreover, these indicators are an instruction to encourage strides in building a system's resilience throughout its entire operation, and they include identifying risks when proposing the design of early-warning systems to raise awareness (Ciftcioglu, 2017). However, in order to be exclusive for their systems, the effectiveness of resilience indicators must be well-constructed with regard to strategically combining the related dimensions of economics, society, and the environment. The integration cannot be neglected because such dimensions are imperative components, which introduce adaptive and transformative capacities to counter the effects of change. More importantly, to generate practical indicators for quantifying and instructing schemes, they must be translated from subjective insights into objective insights to make the process more meaningful (Caldwell, 2015).

To integrate the three dimensions with unity and to translate them as explicit insights, there are remarkable disciplines, which can accomplish that goal. According to Bennett (2010), the five livelihood assets are viable. This framework deals with vital abilities and resources that humans need to form the means for sustainable living. Nevertheless, the framework should be complemented with social approaches, such as Grounded Theory (GT) and Agent-based Models so that the integration of the natural and social sciences with theoretical perspectives can be authorized. This can be facilitated via interviews and observational approaches, the outcomes of which can evolve as theories that are relevant to its specific contexts (Glaser \& Strauss, 2017). In addition, incorporating Technography is recommended (Quinlan et al., 2015). Technography is an interdisciplinary methodology, which combines with qualitative and quantitative methods. It benefits the users in terms of analyzing the relationship between humans and technologies, which have been adopted and/or adapted and which exist in a system's distinct contexts to achieve their satisfactory consequence. Namely, technography can tailor a range of natural and social scientific phenomena with research methods, such as conducting interviews and focus group discussions with the goal of generating constructive questions to enable the researchers to learn about the participants' motives, purposes, and rationales, which underlie his/her activities (Jansen \& Vellema, 2011).

Moreover, thirteen indices, called "behavior-based indicators", are optional (Cabell \& Oelofse, 2012). These indicators have been praised given that they have been 
gathered from pragmatic ideas and actions, which are necessary for building and maintaining resilience in social-ecological systems. However, the behavior-based indicators are unable to be used as a universal standard for measuring the resilience of all systems. Originally, they were developed without the orientation to build the resilience of a specific system although the nature of resilience is significantly dependent upon the interactions of its components across the spatial and temporal scales (Ciftcioglu, 2017). This implies that in order to become amalgamated, the behavior-based indicators still require a suitable discipline that will not only engage the stakeholders, but as a consequence, will draw them into the process of becoming aware of how they can interact with explicit components within their system, but they can also assist in obtaining an exploratory framework for defining a targeted system (Folke et al., 2021). The framework can be formed by a participatory approach that allows the owners of a system to impart the history of the whole system and its related activities, including those interactions between the system and the environments. This attempt contributes to the subjectivity of their own goals, including carrying out constructive inquiries and discussions about quantitative tools and their response scales, which are exclusive in order to measure the resilience of a system (Van Oudenhoven et al., 2010). Importantly, conducting the procedure iteratively is the norm in the process because despite the dynamic changes, many components, which are relevant to enhancing the system's resilience, are, on any occasion, laborious to capture by utilizing the approaches of the hard system and the soft system. For instance, the components of reflection consist of the systemic learning that individuals have gleaned from the past and their ability to assign future decision-making processes that will enable them to make adaptations in the face of change and inclusiveness, which represents the engagement of different actors, who bring their diverse perspectives that are aimed at building resilience (Wulandari, 2021). These are only simple examples, which cannot be constructed as quantified tools if the assistance of the social approaches were to be absent from the process of developing indicators conduct iteratively (Figueiredo et al., 2018).

Regarding the academicians' opinions, when the development of resilience indicators takes place, a greater interpretation of the related dimensions of interesting systems should be prioritized and defined by a suitable participatory discipline (Folke, 2016). It is imperative to achieve this because the precision of building resilience and assessing the results cannot be determined in the economic, ecological, social, environmental, or political dimensions as a separable contemplation (Bene, 2013). Nonetheless, amalgamating these dimensions into a comprehensive set is not an easy task and may require an additional approach because the dimensions, which are tied to the attributes, are generated by people, who have different experiences and assets. In order that this complexity can be solved, the Delphi method is praised as one of the practical tools (Giannarou et al., 2014). The Delphi method allows stakeholders to work towards a mutual agreement by circulating a series of questionnaires and releasing the relevant feedback until a consensus is established. Furthermore, since the Delphi method aggregates both qualitative and quantitative aspects, it has the potential to reach rational opinions about questions, for which there are no absolute answers (Ramos et al., 2016).

In this study, the method of developing the resilience indicators for organic rice production in the central portion of Northeastern Thailand by applying resilience theories has been presented (Cabell \& Oelofse, 2012), and it has been combined with 
the Delphi method (Giannarou et al., 2014; Ramos et al., 2016) to obtain the results showing consensus, which are illustrated as a specific set of resilience indicators as the outcomes.

The study is both practically and academically vital. Currently, the central portion of Northeastern Thailand is a strategic area for boosting food security and maintaining the ecosystem of organic rice production services (Chuasuwan, 2018). However, many challenges are still visible (Poungchompu \& Chantanop, 2016). These constraints have been influenced by topography and variability in politics and climate, which have resulted in delays in the process of lifting local farmers out of vulnerability (FAO, 2019). Moreover, resilience studies in Thailand, especially those which have focused on organic rice production, are scarce because among stakeholders, the core nature of resilience ranges from vague and arduous to savvy (ACT, 2020). The results have benefitted from ongoing national policies, such as the National Organic Farming Action Plan and the Sustainable Rice Platform Standards (Suebpongsang et al., 2020). They have also raised awareness among local organic farmers on the topic of how to build resilience so that they can cope with various changes. Not all agricultural systems can fully benefit from resilience, but organic rice production is a system that allows farmers to use on-farm resources combined with indigenous knowledge to carry out adaptations, rather than to simply rely upon utilizing expensive external inputs. This is particularly suitable for Thai organic farmers because most of them are smallholder farmers, who are looking for potentially affordable solutions that can be implemented as practices on their farms (Panpakdee, 2018).

\section{METHODS}

\subsection{Study Site}

This study was conducted from February to mid-May of 2021 in three provinces located in the central portion of Northeastern Thailand, namely Khon Kaen, Kalasin, and Maha Sarakham. Khon Kaen is one of the four major cities of Northeastern Thailand (Isan) along with Udon Thani, Nakhon Ratchasima, and Ubon Ratchathani. The province is located on the Korat Plateau and has an elevation of 187 meters. In this area, rice is the top grown plant (NESDC, 2019). Kalasin lies on the eastern bank of the Bao River on a major road from Khon Kaen to Sakon Nakhon. This province is known for its livestock, as well as for its conventional and organic rice cultivation areas in the river valleys. Meanwhile, Maha Sarakham is located at the junction of a road on a bend of the Chi River. Organic rice is widely grown in the surrounding region, especially in the shallow river valleys (Office of National Statistic, 2020).

In summary, these provinces are in a tropical savanna climate zone and have sandy saline soils with low fertility. The average rainfall generally varies from 1,000 to $1,500 \mathrm{~mm}$, and rainfall is unevenly distributed during the rainy season (May to October) with over $80 \%$ occurring during the months of August and September. Moreover, approximately only $13.61 \%$ of this area's farmlands are supplied with irrigation systems (Royal Irrigation Development, 2018). However, they have become the predominant organic rice production areas in Northeastern Thailand due to the continual support of governmental agencies, academic institutes, and Non-Governmental Organizations (NGOs), which has continued since their inception (NESDC, 2019). Moreover, regarding agricultural development, these provinces are Thailand's strategic areas due to their abundance of fertile soil and commercial opportunities, including devoted cultivators. These are all vital factors that have allowed the area to become sustainable for organic 
rice production (ACT, 2020).

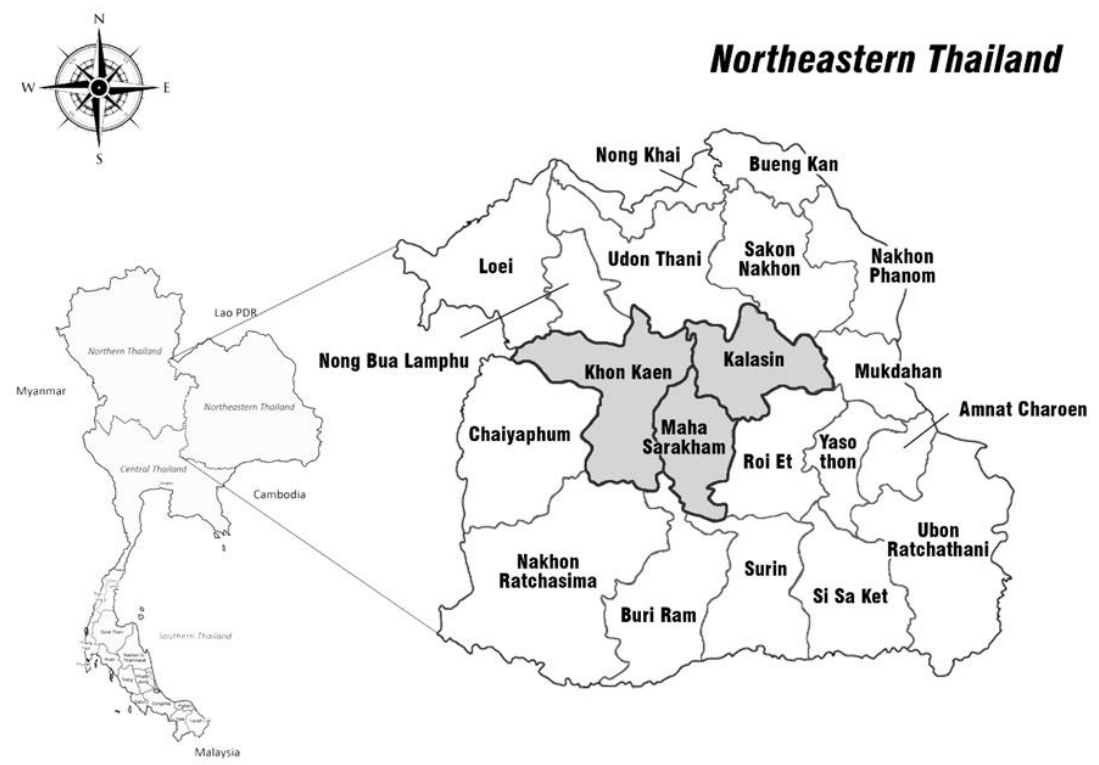

Figure 1. The sites of the study

\subsection{Sampling Procedure}

Due to the marginal number of organic rice farmers in Thailand, a purposive sampling survey was undertaken by utilizing the Organic Agriculture Certification Thailand's database to provide the empirical data. The participants consisted of a total of 47 organic rice farmers, who had previously been recognized as being skillful in organic rice production (ACT, 2020) (Table 1). Initially, this method was selected because the study of developing resilience indicators requires informants, who have a sufficient level of knowledge about the management of organic rice farms (Ciftcioglu, 2017). Also, the informants shared a similar social-ecological context, which was, in this case, the central portion of Northeastern Thailand. This criterion was requisite to ensure that obtainable indices would be the outcome and that they would be workable across the spatial-temporal scales of the three provinces (Quinlan et al., 2015).

The informants consisted of forty-three males (91.49\%) and four females (8.51\%). The mean values of their ages and their years of experience being certified organic farmers were 55.08 and 11.30 years, respectively. Most of them had completed primary school (65.96\%), which was followed by those who had completed secondary school $(23.40 \%)$, and those with higher levels of education (10.64\%). Furthermore, the informants, on average, had had 8.53 years of experience in organic rice production, and the sizes of their farms had ranged from 0.64 to 2.28 hectares.

Table 1. The number of participants involved in the study sites

\begin{tabular}{llcc}
\hline \multicolumn{1}{c}{ Provinces } & \multicolumn{1}{c}{ Districts } & $\begin{array}{c}\text { No. of Sampling } \\
\text { Participants }\end{array}$ & $\begin{array}{c}\% \text { of Total Sampling } \\
\text { Participants }\end{array}$ \\
\hline Khon Kaen & $\begin{array}{l}\text { Mueang Khon Kaen, Phra Yuen, } \\
\text { and Kranuan }\end{array}$ & 19 & 40.43 \\
Kalasin & Mueang Kalasin and Kuchinarai & 16 & 34.04
\end{tabular}




\begin{tabular}{|c|c|c|c|}
\hline Provinces & Districts & $\begin{array}{l}\text { No. of Sampling } \\
\text { Participants }\end{array}$ & $\begin{array}{c}\% \text { of Total Sampling } \\
\text { Participants }\end{array}$ \\
\hline $\begin{array}{l}\text { Maha } \\
\text { Sarakham }\end{array}$ & $\begin{array}{l}\text { Mueang Maha Sarakham and } \\
\text { Kantharawichai }\end{array}$ & 12 & 25.53 \\
\hline & Total & 47 & 100.00 \\
\hline
\end{tabular}

\subsection{Data Collection}

The data collection was divided into two steps. Firstly, to become more aware and to determine if resilience building is vital for coping with changes in organic rice production and how it could be vital, a systematic review of the relevant literature was implemented to investigate documents that existed in the online databases (Snyder, 2019). The search for keywords was conducted with the search engine ISI Web of Knowledge (WOK) using the key topic terms of "resilience" AND "organic rice*". WOK was selected given that it is one of the most current and comprehensively utilized search engines that is employed to analyze the peer-reviewed literature, in which one of the most outstanding contents is Essential Science Indicators (ESI) (Jasco, 2005). More importantly, it is one of the most trusted global citation databases and has been advocated by 9,000 leading academic, corporate, and government institutions, including millions of researchers (Else, 2018). However, such a review included only English literature, which had been published between 2013 and 2020. The existing literature before 2012 was not reviewed as the essence of resilience knowledge in agroecosystems was first elaborated in Cabell and Oelofse's article (2012). This search retrieved 183 documents, whose titles and abstracts were examined to assess their appropriateness for inclusion in the final review. In some cases, a meticulous full-text review was, nonetheless, implemented to evaluate suitability (Glaser \& Strauss, 2017).

Secondly, a semi-structured interview format was followed. The participants were individually questioned with a series of preliminary questions to authorize them by appraising their agricultural backgrounds and the new supplementary data, which was valuable for the data collection. Next, the participants were asked to use their knowledge and perspectives to visualize "a desirable farm," which would be the ideal organic rice farm that could be established by components, and which could assist in establishing the attributes of resilience across spatial and temporal scales. Nevertheless, it was imperative that the desirable farm, which was to be constructed, be accompanied by assets, factors, or elements, the attributes of which could perform as social-ecological indicators to quantify and monitor the resilience of the desirable farm (Darnhofer, 2010). In this stage, the behavior-based indicators in agro-ecosystems (Cabell \& Oelofse, 2012) were applied to produce constructive questions, which covered the economic, social, and environmental dimensions and which focused on how to best implement both coping strategies and adaptive strategies to cope with changes (FAO, 2012).

\subsection{Data Analysis}

The interviews were recorded, and notes were taken. Then, the data was transcribed as descriptive and reflective data, which was suitable for conversion into the useful meanings of the units by 3 procedures of qualitative data analysis: (1) data reduction, (2) data display, and (3) concluding (Miles et al., 2014).

Based on the first two procedures, the descriptive and reflective data were analyzed and assigned into initial sets of codes to illustrate the relationship between the criteria and the resilience properties in the agro-ecosystems. Thereafter, the code 
sets were analyzed to separate the ambivalent data and were then examined and placed into classified codes with similar attributes. Finally, these were categorized in the same groups, while others, which were irrelevant, were discarded. The groups of the classified codes were then verified. Consequently, twenty-three indicators were crystallized and were then separated with respect to the four imperative resilience features (Folke, 2016).

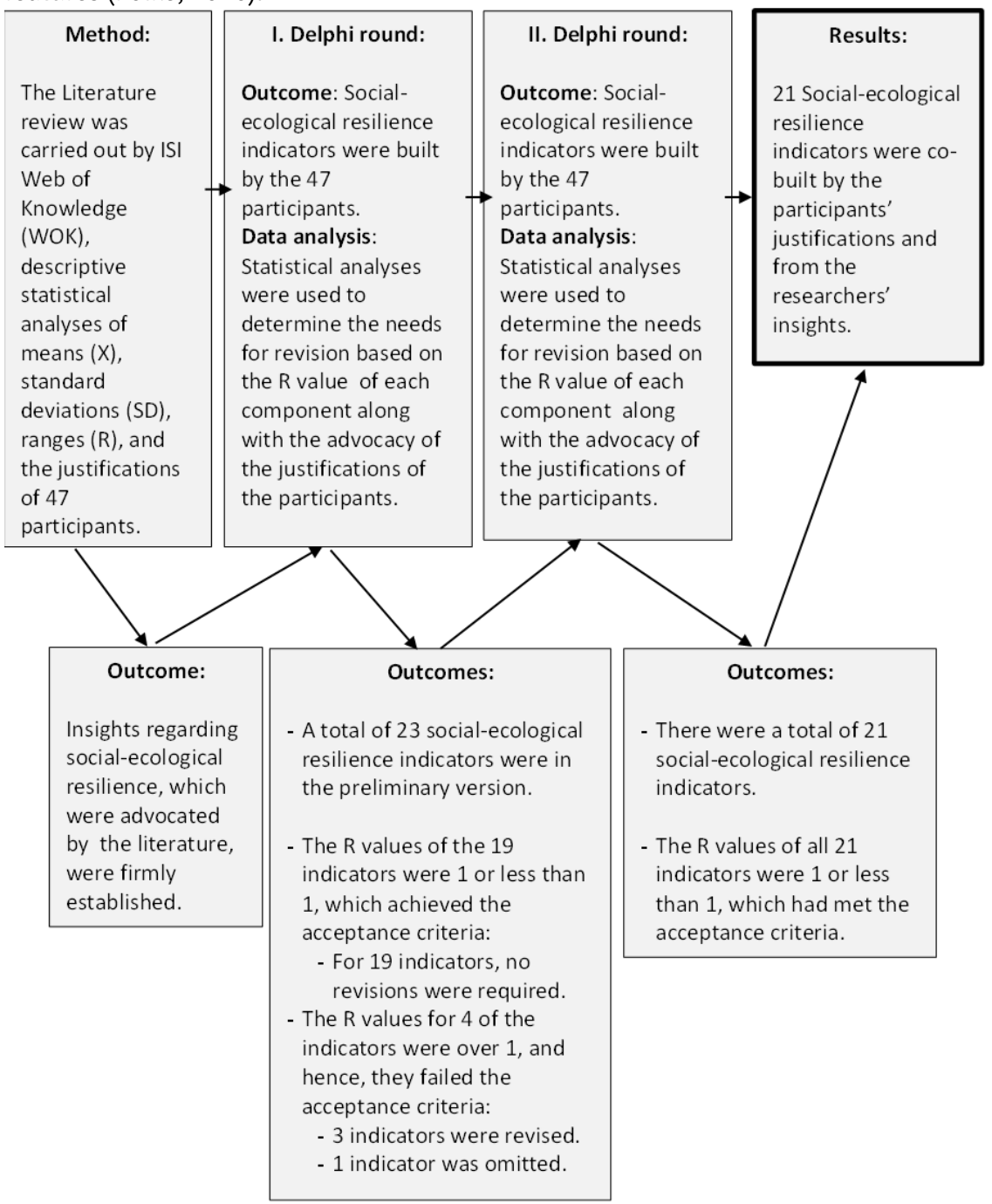

Figure 2. The conceptual framework for developing the social-ecological resilience indicators

\subsection{Delphi Round}

At this point, the twenty-three indices were not yet social-ecological resilience indicators of organic rice production because they needed to be verified by the Delphi method. Every acquired indicator was revised in the form of a questionnaire, and the 23 
indices were divided into four headings with the following titles: "Learning to live with change and uncertainty," "Nurturing diversity for reorganization and renewal," "Combining different types of knowledge for learning," and "Creating opportunities for self-organization” (Folke, 2016) (Table 2).

Before the beginning of the first round of the Delphi method, all participants were reached by phone and were meticulously informed about the Delphi method and the purpose of this study.

The participants, at least 5 persons per region at a time, were questioned and asked to address the missing indicators, which were not untraceable from the first time of the data collection. Concurrently, they were solicited to eradicate some indicators due to their vagueness for devising the desirable farm. Under the 4 headings, a 5-point Likert scale was applied to perform the revision processes with each indicator being scored as follows: "1 - not at all helpful," "2 - not so helpful," "3 - somewhat helpful," “4 - very helpful," and "5 - extremely helpful.” The options were displayed as a visual presentation to assist the participants to assign the scaled answers more conveniently (Dawes, 2008). However, based upon the opinions of the participants, it was necessary for this process to be accompanied by ascription and correction. Consequently, the preliminary version of the social-ecological resilience indicators of organic rice production was generated

\subsubsection{Data analysis of the I. Delphi Round}

After the I. Delphi tour, each point given to the indicator was evaluated by using an SPSS 23.0 program to compute the arithmetic means ( $\mathrm{x}$ ), the standard deviations $(\mathrm{sd})$, and the interquartile ranges $(\mathrm{R})$.

According to this study, the " $R$ " value is particularly significant because it represents the distance between the 25 th percentile and the 75 th percentile values in judgments, with a smaller value of $\mathrm{R}$ indicating a larger consensus. The indicators with "R" values at 1 and less than 1 were considered to have met the acceptance criteria, whereas items with "R" values of greater than 1 were determined not to have met the acceptance criteria (Table. 2). Specifically, if the $R$ value was less than 1 , it meant that more than $50 \%$ of all opinions had fallen at a certain point on the scale, which indicated that the participants had reached a consensus. Meanwhile, an $\mathrm{R}$ value of zero indicated that the agreement among the participants could be considered as valid (Ramos et al., 2016).

Table 2. The preliminary version of the social-ecological resilience indicators produced by I. Delphi round

\begin{tabular}{|c|c|c|c|}
\hline \multirow{2}{*}{ Indicators } & \multicolumn{3}{|c|}{ Statistical values } \\
\hline & $\mathrm{X}$ & SD & $\mathbf{R}$ \\
\hline \multicolumn{4}{|l|}{ Heading 1: Learning to live with change and uncertainty } \\
\hline 1. The educational accomplishments of the organic rice farmers & 4.49 & 0.51 & 1 \\
\hline 2. The ages of the organic rice farmers & 3.62 & 0.49 & 1 \\
\hline 3. Experience in organic rice production & 4.47 & 0.50 & 1 \\
\hline 4. The availability of an exclusive organic rice mill in the community & 5.00 & 0.00 & 0 \\
\hline 5. A sufficient number of household laborers & 4.43 & 0.50 & 1 \\
\hline 6. An abundance of life-long learning skills & 4.57 & 0.50 & 1 \\
\hline 7. The full ownership of all land used to grow organic rice & 5.00 & 0.00 & 0 \\
\hline \multicolumn{4}{|l|}{ Heading 2: Nurturing diversity for re-organization and renewal } \\
\hline 8. The diversity of soft loan sources* & 1.32 & 1.20 & 2 \\
\hline 9. The diversity of market outlets & 5.00 & 0.00 & 0 \\
\hline
\end{tabular}




\begin{tabular}{|c|c|c|c|c|}
\hline \multirow{2}{*}{\multicolumn{2}{|c|}{ Indicators }} & \multicolumn{3}{|c|}{ Statistical values } \\
\hline & & $\mathrm{X}$ & SD & $\mathbf{R}$ \\
\hline & The diversity of organic certification & 3.47 & 0.50 & 1 \\
\hline \multicolumn{5}{|c|}{ Heading 3: Combining different types of knowledge } \\
\hline 11. & $\begin{array}{l}\text { The competence to do commerce in both online and offline } \\
\text { marketplaces }\end{array}$ & 4.68 & 0.47 & 1 \\
\hline 12. & Manure management techniques & 4.49 & 0.51 & 1 \\
\hline 13. & Having knowledge of processed products & 5.00 & 0.00 & 0 \\
\hline \multicolumn{5}{|c|}{ Heading 4: Creating opportunities for self-organization } \\
\hline 14. & $\begin{array}{l}\text { Augmenting the officers' abilities to adapt to changing } \\
\text { knowledge** }\end{array}$ & 2.96 & 0.81 & 2 \\
\hline 15. & The availability of local green markets & 4.47 & 0.50 & 1 \\
\hline 16. & $\begin{array}{l}\text { The consistency of necessary support from related } \\
\text { organizations }\end{array}$ & 5.00 & 0.00 & 0 \\
\hline 17. & $\begin{array}{l}\text { Being surrounded by favorable social environments with } \\
\text { respect to organic rice production }\end{array}$ & 3.55 & 0.50 & 1 \\
\hline 18. & Premium prices are guaranteed by related organizations & 5.00 & 0.00 & 0 \\
\hline 19. & $\begin{array}{l}\text { The effective capacity of the group leader to collaborate with } \\
\text { organizations }\end{array}$ & 4.49 & 0.51 & 1 \\
\hline 20. & The efficiency of agri-food logistics & 3.53 & 1.08 & 1 \\
\hline 21. & Sound infrastructure & 3.68 & 0.81 & 1 \\
\hline 22. & An abundance of irrigation systems* & 2.85 & 1.49 & 3 \\
\hline 23. & The stability of abundant rainfall patterns* & 3.02 & 0.79 & 2 \\
\hline
\end{tabular}

Note: *There is a need for revision given that the participants' justifications and the 'R' values are irrelevant. **There is no need for revision given that the participants' justifications and the 'R' values are relevant.

The contemplation about the revision of each indicator was adjudicated following the $\mathrm{R}$ values. However, the participants' justifications were additionally taken into consideration in order to enhance the process of interpreting the necessity of the indicators. In this respect, a few indicators, whose $\mathrm{R}$ values were higher than 1 , were customarily seen to be unacceptable criteria. If the $R$ value of an indicator was deemed as irrelevant from the significant viewpoints of most participants, the indicators were then re-evaluated on a one-by-one basis. Therefore, these indicators were revised and re-added to make them available for the next II Delphi tour evaluations.

\subsection{Delphi Round}

The II. Delphi round was carried out to conclude the data validation with the same forty-seven participants.

Initially, the participants were shown the entirety of the X, SD, and R values, which had been paired with the rationales from the I. Delphi survey. The statistical values were interpreted and described in ordinary language to better help the informants perceive the information. In order to conclude the II. Delphi round, they were, next, asked to ponder each customized indicator and to score each item using the 5-point Likert-type scale, which was similar to the I. Delphi round.

\subsubsection{Data analysis of the II. Delphi round}

Each score, which was given to the indicators, was calculated to produce the statistical results of the $\mathrm{X}, \mathrm{SD}$, and $\mathrm{R}$ values. To determine the degree of importance and the degree of consensus between the first and second rounds of the Delphi method, the computed $\mathrm{R}$ values were compared individually. After the aforementioned processes and the instructions on the I. and II. Delphi tours had been completed, the final version 
was formulated, ordered, and determined to be suitable for academic exploitation. Finally, these were named as the social-ecological resilience indicators of organic rice production for the central portion of Northeastern Thailand (Table 3).

Table 3. The final version of the social-ecological resilience indicators produced by the II. Delphi round

\begin{tabular}{|c|c|c|c|}
\hline \multirow{2}{*}{ Indicators } & \multicolumn{3}{|c|}{ Statistical values } \\
\hline & $\mathrm{x}$ & SD & $\mathrm{R}$ \\
\hline \multicolumn{4}{|l|}{ Heading 1: Learning to live with change and uncertainty } \\
\hline 1. The educational accomplishments of the organic rice farmers & 4.49 & 0.51 & 1 \\
\hline 2. The ages of the organic rice farmers & 3.62 & 0.49 & 1 \\
\hline 3. Experience in organic rice production & 4.47 & 0.50 & 1 \\
\hline 4. The availability of an exclusive organic rice mill in the community & 5.00 & 0.00 & 0 \\
\hline 5. A sufficient number of household laborers & 4.43 & 0.50 & 1 \\
\hline 6. An abundance of life-long learning skills & 4.57 & 0.50 & 1 \\
\hline 7. The full ownership of all land used to grow organic rice & 5.00 & 0.00 & 0 \\
\hline $\begin{array}{l}\text { 8. The accessibility to the services of the Bank for Agriculture and } \\
\text { Agricultural Cooperatives (BAAC). }\end{array}$ & 4.53 & 0.50 & 1 \\
\hline \multicolumn{4}{|l|}{ Heading 2: Nurturing diversity for re-organization and renewal } \\
\hline 9. The diversity of market outlets & 5.00 & 0.00 & 0 \\
\hline 10. The diversity of organic certification & 4.17 & 0.79 & 1 \\
\hline 11. The diversity of agricultural water sources & 5.00 & 0.00 & 0 \\
\hline \multicolumn{4}{|l|}{ Heading 3: Combining different types of knowledge } \\
\hline $\begin{array}{l}\text { 12. The competence to do commerce both in online and offline } \\
\text { marketplaces }\end{array}$ & 5.00 & 0.00 & 0 \\
\hline Manure management techniques & 4.49 & 0.51 & 1 \\
\hline Having knowledge of processed products & 5.00 & 0.00 & 0 \\
\hline \multicolumn{4}{|l|}{ Heading 4: Creating opportunities for self-organization } \\
\hline The availability of local green markets & 4.47 & 0.50 & 1 \\
\hline $\begin{array}{l}\text { The consistency of necessary support from related } \\
\text { organizations }\end{array}$ & 5.00 & 0.00 & 0 \\
\hline $\begin{array}{l}\text { Being surrounded by favorable social environments for organic } \\
\text { rice production }\end{array}$ & 3.55 & 0.50 & 1 \\
\hline Premium prices are guaranteed by related organizations & 5.00 & 0.00 & 0 \\
\hline $\begin{array}{l}\text { 19. The effective capacity of the group leader to collaborate with } \\
\text { organizations }\end{array}$ & 4.49 & 0.51 & 1 \\
\hline The efficiency of agri-food logistics & 4.66 & 0.48 & 1 \\
\hline Sound infrastructure & 3.68 & 0.81 & 1 \\
\hline
\end{tabular}

\section{RESULTS AND DISCUSSIONS}

Initially, the 23 social-ecological resilience indicators were formulated by the forty-seven participants. However, after the I. and the II. Delphi tours, only 21 indices remained. The step-by-step origins of these indices are described as follows:

In the first round, these indicators, which were embedded in the 4 headings associated with building resilience in agro-ecosystems, were added to the questionnaire (Folke, 2016). The indicators were necessarily tied to the headings for two reasons: the theoretical aspects and the practical aspects, which they covered. Theoretically, these headings are qualities, which have been vital to the absorption of all kinds of disturbances in agro-ecosystems and in which uncertainty has been surely influenced by the interactions of physical, biological, and socio-economic subsystems for managing agricultural activities (Caldwell, 2015). Practically, the rearrangement in form was carried out in order to give a functional advantage for the next survey. 
Regarding the results from the questionnaires, they indicated that 19 of the 23 indicators had had $R$ values of between 0 and 1 , which showed that it was unnecessary to re-examine them since their statistical values had met the acceptance criteria (Fig. 2). Once more, from among the 23 indicators, 4 of them had failed to meet the acceptance criteria, making it necessary for them to be revised. Nevertheless, not all of the indicators were approved to enter the revision process. The indicator of "Extension officers' adaptability to changing technologies and knowledge" was ignored not only because its ' $R$ ' value was over 1 , but also because with respect to the practice of resilience building, the participants' justifications about favoring its role had been unanimous and vague. This phenomenon differed from the remaining three indicators ("the diversity of soft loaning sources," "the abundance of irrigation systems," and "the stability of abundant rainfall patterns"). Although their ' $R$ ' values were more than 1 (Table 2), we considered revising them given that dissociation had been explicitly found to exist between the statistical values and their ascriptions. Most participants solidly indicated that the existence of water sources like rainfall and surface water (irrigation) is the foundation of agriculture, especially for organic rice farming (Sangkhaphan \& Shu, 2019). This is because those water sources are not only essential for nourishing rice production, but they are also important in suppressing weeds and in enhancing soil structure by allowing for better nutrient retentive abilities (Polthanee, 2018). Meanwhile, the rationale about the diversity of sources for soft loans was similar. The participants' views on that issue indicated that they were smallholder farmers. Therefore, they were seeking sources of loans that had a reasonable percentage of interest to invest in so that they could compensate for their normality of limited assets (Darnhofer, 2010).

The II. Delphi round began with the revised questionnaire, which was comprised of the 21 indicators that were available to the participants, because the diversity of sources for soft loans (Table 2) had been corrected due to the rational and pragmatic manner in which the accessibility to services at the Bank for Agriculture and Agricultural Cooperatives (BAAC) (Table 3) had been facilitated. Meanwhile, the abundance of irrigation systems and stability of abundant rainfall patterns (Table 2) were amalgamated into a single unit: "the diversity of agricultural water sources" (Table 3). The amalgamation was motivated by the participants' opinions, in which they pointed out that both irrigation systems and rainfall are entirely accountable for organic rice production. However, the degree of the importance of water sources was found to vary depending upon each participant's social-ecological context. For instance, the plenitude of rain had had a limited impact on those participants in the urban lowlands, where irrigation services can be conveniently obtained. Conversely, the role of rainfall was likely to be more significant in the case of those participants, who were growing organic rice in the highlands, where irrigation is scarce or absent (Panomsak \& Sakdapolrak, 2012) because rainfall may be the single source, which maintains their crops (Olayide et al., 2016). Even underground water sources on the land, such as wells and ponds, which are man-made attempts at construction, are likely to malfunction if the reinforcement of rainfall is absent (Sangkhaphan \& Shu, 2019). Therefore, these two indicators were recommended to amalgamate the process and make it more holistic and precise so that resilience can be monitored.

The implementation of the II. Delphi tour was not as complicated as the I. Delphi. The total of 21 indicators were all scored with " $R$ " values ranging from 0 to 1 , which firmly indicated that consensus had been achieved (Table 3). However, the mean scores 
of two of the indicators had shifted from the original. The "Diversity of organic certification" and the "Efficiency of agri-food logistics" were modified from 3.53 to 4.66 and from 3.47 to 4.17 , respectively (Table 2 , Table 3 ).

Consequently, the 21 indexes, which are called the social-ecological resilience indicators of organic rice production in the central portion of Northeastern Thailand, were formulated and categorized with respect to the four imperative resilience features as follows (Folke, 2016): (1) the feature of "Learning to live with change and uncertainty," consisted of eight items; (2) the title of "Nurturing diversity for reorganization and renewal" was comprised of three items; (3) three indicators were under the feature of "Combining different types of knowledge for learning," and (4) seven indicators were under the feature of "Creating opportunity for self-organization" (Table 3). These indices were able to perform reliably both for quantifiable assessment and for farmer guidance. These characteristics existed because the 21 indices had been systemically instituted within the participants' historic, technological, social, and ecological contexts, which are all vital factors when seeking to implement adaptations and make transformations to counter disturbances in organic rice production systems (Ciftcioglu, 2017; Panpakdee \& Limnirankul, 2018).

\section{CONCLUSION AND RECOMMENDATIONS}

This study has presented how to apply the Delphi method to develop the socialecological resilience indicators for organic rice production in the central portion of Northeastern Thailand. For resilience studies, this is vital because it requires both effective implementation and the co-establishment of policies, which are generated by interactions between farmers and related organizers (Paunglad, 2019). The advantage of the Delphi method is that it assists in overcoming the complex nature of socialecological resilience because resilience systems need the system owners to establish the definition of resilience, including its boundaries and supportive components (Samaraweera, 2020).

Although this study was facilitated by utilizing the Delphi method, the nature of resilience often creates obstacles to settling the participants' general agreement, which has been influenced by the dissimilar social-ecological perspectives of the participants. The final section will discuss some of the obstacles, which were discovered during this investigation.

4.1 The differences in the social-ecological perspectives among the participants

As previously mentioned, the Delphi method was conducted in two rounds. Within the rounds, the acceptance criteria had been qualified by several indicators because with the supplementation of the favorable justifications by the participants, the "R" values had been found to range from 0 to 1 . Concurrently, few of the indicators had failed to reach that criterion. However, this did not imply that these indicators should be immediately omitted. Instead, some of them needed to be retained for further considerations in order to determine whether or not their ' $R$ ' values would be relevant in light of the opinions influenced by the social-ecological contexts of the participants, including the distinctiveness of experiences and the attitudes of each individual.

In this study, one indicator, "The extension officers' adaptability to changing knowledge," had been neglected in the I. Delphi round because its ' $R$ ' value and the participants' opinions had been interrelated (Table 2). The role that the extension officers play in disseminating up-to-date knowledge is admittedly significant in building resilience because adaptations and coping strategies are partly based on the officers' 
intelligence (Panpakdee, 2018). However, this represented the opinions of only a small number of the participants and was consequently vetoed by the majority of the participants. Most participants indicated that it can certainly be a handicap when extension officers are constantly attempting to educate organic farmers. In regard to this issue, when having to rely on the extension officers, the farmers' competence in the area of self-dependence can be gradually lost. This can lead to the deterioration of lifelong learning abilities, which have been cited as key indicators for building resilience (Table 2, Table 3). Therefore, according to the organic farmers, they must be self-aware and pro-active in searching for knowledge because at present, gaining knowledge is not difficult for them as it once was.

Conversely, even though their ' $R$ ' values were greater than 1 , three indicators (i.e., "The diversity of soft loaning sources," "The abundance of irrigation systems," and "The stability of abundant rainfall patterns,") were granted the opportunity to be further discussed in the II Delphi method (Table 2 ) because in building resilience, the roles that these indicators play are enormous. However, their interquartile range $(R)$ values were found to be statistically insignificant given the participants' varied social-ecological contexts.

Regarding that, for instance, the diversity of loaning sources, whether subsidized by the government or by private banks, was cited as vital to building resilience. Moreover, the reasoning was that the presence of such financial sources has been beneficial for introducing tools, labor, and new investments, which can help to manage any crises (Duchek et al., 2020). However, the supportive rationales of it are hypothetical, rather than practical. Most informants indicated that the majority of ordinary Thai cultivators, especially those in the central portion of Northeastern Thailand, are marginal. This factor causes them to experience difficulties when they are seeking to be granted soft loans by both government and public institutes since their collateral is scarce, and there is the possibility of forfeiture (ACT, 2020).

Nonetheless, it is undeniable that capital is essential for organic rice production because the farmers' decisions on what, when, and how to produce are generally influenced by their financial means (Ruiz, 2014). After obtaining feedback, the information was then applied as a basis for adjusting the indicator to create a new one: 'The accessibility to the services of the Bank for Agriculture and Agricultural Cooperatives (BAAC).' Reaching a consensus on this matter had to wait until the next discussion. Then, in the II. Delphi round, the participants affirmed the fact that this revision had not only been more practical, but it had also been more universal for them. Their reasoning was that the BAAC is the Thai government bank, and that the bank's mission is to subsidize smallholder cultivators like them so that they could carry out agriculture and other related-agriculture activities (FAO, 2012).

Another example illustrated an obstacle, which had been influenced by the differences in social-ecological contexts and had made it difficult to finalize a consensus. Initially, the abundance of irrigation systems and the stability of abundant rainfall patterns had been separately addressed as vital resilience indicators (Table 2). Principally, the prosperity of irrigation systems was cited by the participants in Kalasin, where most of the organic rice areas are located in the lowlands, which are satisfactorily nourished by local irrigation canals. This phenomenon stands in contrast to the experiences of the participant farmers in Khon Kaen and Maha Sarakham, whose farms are located in the highlands, where agriculture is rain-fed and where their farms are noticeably supported by stable patterns of rainfall. 
Once more, after receiving that information, it was used as a basis for merging the two indicators into a new single one: "The diversity of agricultural water sources" (Table 3). The merging of these indicators was based on the deliberation that all water types can play pivotal roles in all kinds of agriculture (Panpakdee, 2018). As the second round of the Delphi method began, the newly revised indicator was shown to all informants via a questionnaire survey. At this time and without meticulous discussion, this indicator was determined to have accomplished the acceptance criteria. When every participant was allowed to understand the comprehensive knowledge and the rationale of the indicator, which was shared by the others, such feedback helped them to achieve consensus more readily.

Author Contributions: Chaiteera Panpakdee: Conceptualization, Methodology, Data collection; Analysis, Writing (draft preparation, reviewing, editing), Suchint Simaraks: Conceptualization, Chanidapa Sookcharoen: Content analysis, Writing and Correction of writing language.

Conflicts of Interest: The authors declare there have been no conflicts of interest found throughout the research.

Ethical Statement: The research was approved by Khon Kaen University's Review Board of Ethics in Human Research.

Acknowledgments: This study was financially supported by the Young Researcher Development Project of Khon Kaen University. We would like to express our gratitude for the full support of all the organic farmers, who participated at the study sites.

\section{REFERENCES}

ACT. (2020). The list of organic operators. Agriculture Certification Thailand (ACT). Retrieved from https://www.pier.or.th/wpcontent/uploads/2019/12/pier_dp_122.pdf

Allen, C. R., Angeler, D. G., Garmestani, A. S., Gunderson, L. H., \& Holling, C. S. (2014). Panarchy: theory and application. Ecosystems, 17(4), 578-589. https://doi.org/10.1007/s10021-013-9744-2

Amare, M., Jensen, N.D., Shiferaw, B., \& Cisse, J.D. (2018). Rainfall shocks and agricultural productivity: Implication for rural household consumption. Agricultural Systems, 166, 79-89. https://doi.org/10.1016/j.agsy.2018.07.014

Bene, C. (2013). Towards a Quantifiable Measure of Resilience. Special Issue: Towards a Quantifiable Measure of Resilience, 434, 1-27. https://doi.org/10.1111/j.2040-0209.2013.00434.x

Bennett, N. J. (2010). Sustainable Livelihoods from Theory to Conservation Practice: An Extended Annotated Bibliography of Sustainable Livelihoods Approaches in Protected Areas Community Research. PAPR Working Paper Number 1. University of Victoria, Victoria, British Columbia, Canada. Available at https://dspace.library.uvic.ca/bitstream/handle/1828/4461/sustainablelivelihoods.pdf?sequence $=1$ \&isAllowed $=y$

Cabell, J., \& Oelofse, M. (2012). An indicator framework for assessing agroecosystem resilience. Ecology and Society, 17(1), 18. https://doi.org/10.5751/ES-04666170118

Caldwell, W. (2015). The agricultural system: Components, linkages, and rationale. Green Belt. Retrieved from https://d3n8a8pro7vhmx.cloudfront.net/greenbelt/pages/1402/attachments/ 
original/1434048607/The_Agricultural_System_-_Final.pdf?1434048607

Choundhury, M. I., Haque, C. M., \& Doberstein, B. (2021). Adaptive governance and community resilience to cyclones in coastal Bangladesh: Addressing the problem of fit, social learning, and institutional collaboration. Environmental Science \& Policy, 124, 580-592. https://doi.org/10.1016/j.envsci.2021.08.007

Chuasuwan, C. (2018). Rice industry outlook, 2018-2020. Krungsri Research.

Ciftcioglu, G. C. (2017). Assessment of the resilience of socio-ecological production landscapes and seascapes: A case study from Lefke Region of North Cyprus. Ecological Indicators, 73, 128-138. https://doi.org/10.1016/j.ecolind.2016.09.036

Darnhofer, I. (2010). Strategies of family farms to strengthen their resilience. Environmental Policy and Governance, 20(4), 212-222. https://doi.org/10.1002/eet.547

Dawes, J. (2008). Do data characteristics change according to the number of scale points used? An experiment using 5-point, 7-point and 10-point scales. International Journal of Market Research, 50(1), 61-104. https://doi.org/10.1177\%2F147078530805000106

Duchek, S., Raetze, S., \& Scheuch, I. (2020). The role of diversity in organizational resilience: a theoretical framework. Business Research, 13, 387-423. https://doi.org/10.1007/s40685-019-0084-8

Else, H. (2018). How Unpaywall is transforming open science. Nature, 560(7718), 290292. https://doi.org/10.1038/d41586-018-05968-3

FAO. (2012). Building resilience for adaptation to climate change in the agriculture sector. Proceedings of a Joint FAO/OECD Workshop. Food and Agriculture Organization of the United Nations. Retrieved from http://www.fao.org/3/i3084e/i3084e.pdf

FAO. (2019). Country fact sheet on food and agriculture policy trends (Thailand). Food and Agriculture Organization of the United Nations. Retrieved from http://www.fao.org/3/l8683EN/i8683en.pdf

Figueiredo, L., Honiden, T., \& Schumann, A. (2018). Indicators for resilient cities. OECD Regional Development Working Papers 2018/02. OECD Publishing. https://doi.org/10.1787/6f1f6065-en

Folke, C. (2016). Resilience (Republished). Ecology and Society, 21(4), 44. https://doi.org/10.5751/ES-09088-210444

Folke, C., Carpenter, S., Elmqvist, T., Gunderson, L., \& Walker, B. (2021). Resilience: Now more than ever. Ambio, 50, 1774-1777. https://doi.org/10.1007/s13280-02001487-6

Giannarou, L., \& Zervas, E. (2014). Using Delphi technique to build consensus in practice. International Journal of Business Science \& Applied Management (IJBSAM), 9(2), 65-82. http://hdl.handle.net/10419/190657

Glaser, B., \& Strauss, A. (2017). The Discovery of Grounded Theory: Strategies for Qualitative Research. Routledge. https://doi.org/10.4324/9780203793206

Imperiale, A., \& Vanclay, F. (2019). Command-and-control, emergency powers, and the failure to observe United Nations disaster management principles following the 2009 L'Aquila earthquake. International Journal of Disaster Risk Reduction, 36, 1-14. https://doi.org/10.1016/j.ijdrr.2019.101099

Jansen, K., \& Vellema, S. (2011). What is Technography? NJAS: Wageningen Journal of Life Sciences, 57(3-4), 169-171. https://doi.org/10.1016/j.njas.2010.11.003 
Jasco, P. (2005). As we may search - Comparison of major features of the Web of Science, Scopus, and Google Scholar citation-based and citation-enhanced databases. Current Science, 89(9), 1537-1547. http://www.jstor.org/stable/24110924

Miles, M., Huberman, M., \& Saldana, J. (2014). Qualitative Data Analysis. A method sourcebook ( $3^{\text {rd }}$ Edition). SAGE Publications.

NESDC. (2019). Gross Regional and Provincial Products. Retrieved from https://www.nesdc.go.th/ewt_dl_link.php?nid=5628\&filename=gross_regiona l

Office of National Statistic. (2020). Statistical yearbook Thailand 2020. Office of National Statistic.

Olayide, O. E., Teteh, I. K., \& Popoola, L. (2016). Differential impacts of rainfall and irrigation on agricultural production in Nigeria: Any lessons for climate-smart agriculture? Agricultural Water Management, 178, 30-36. https://doi.org/10.1016/j.agwat.2016.08.034

Panomsak, P., \& Sakdapolrak, P. (2012). Where the rain falls project. Case study: Thailand. Results from Thung Hua Chang District, Northern Thailand. United Nations University.

Panpakdee, C. (2018). Social-ecological resilience of smallholder farmers for organic rice production in Chiang Mai Province [Doctoral dissertation]. Chiang Mai University.

Panpakdee, C., \& Limnirankul, B. (2018). Indicators for assessing social-ecological resilience: A case study of organic rice production in northern Thailand. Kasetsart Journal of Social Sciences, 39(3), 414-421. https://doi.org/10.1016/j.kjss.2017.07.003

Panpakdee, C., \& Palinthorn, F. (2021). Does the COVID-19 pandemic affect socialecological resilience of organic rice production system in Chiang Mai Province, Thailand? Forest and Society, 5(2), 209-223. https://doi.org/10.24259/fs.v5i2.10642

Paunglad, B. (2019). Problems, Obstacles, and Approaches to Implement Organic Agriculture Policy: Case Study of Growing Organic Rice at Baan Dong Bang, Nong Bo, Ubonratchathani. NIDA Research Journal, 11(1), 1-32.

Polthanee, A. (2018). Cassava as an insurance crop in a changing climate: The changing role and potential applications of cassava for smallholder farmers in Northeastern Thailand. Forest and Society, 2(2), 121-137. https://doi.org/10.24259/fs.v2i2.4275

Poungchompu, S., \& Chantanop, S. (2016). Economic aspects of rice combine harvesting service for farmer in Northeast Thailand. Asian Social Science, 12(8), 201-211. https://doi.org/10.5539/ass.v12n8p201

Quinlan, A., Blázquez, M. B., Haider, J., \& Peterson, G. (2015). Measuring and assessing resilience: Broadening understanding through multiple disciplinary perspectives. Journal of Applied Ecology, 53(3), 677-687. https://doi.org/10.1111/1365-2664.12550

Ramos, D., Pedro, A., \& Paulo, A. (2016). Application of the Delphi Method for the inclusion of externalities in occupational safety and health analysis. DYNA, 83(196), 14-20. https://doi.org/10.15446/dyna.v83n196.56603

Royal Irrigation Development. (2018). Mekong-Loei-Chee-Moon with increasing irrigated area to the real plateau benefits. Royal Irrigation Development. 
Retrieved from https://www.thailandplus.tv/archives/27548

Ruiz, C. (2014). How can finance influence productivity of agricultural firms? World Bank. Retrieved from https://blogs.worldbank.org/allaboutfinance/how-canfinance-influence-productivity-agricultural-firms

Samaraweera, U. (2020). Is resilience a unique extension rather than a rejection of neoliberalism? A critical reading of David Chandler's writings on resilience. International Journal of Disaster Resilience in the Built Environment, 12(5), 528-539. https://doi.org/10.1108/IJDRBE-05-2020-0050

Sangkhaphan, S., \& Shu, Y. (2019). Impact of rainfall on agricultural growth in Thailand: Evidence in farming and fishing activities. Journal of Economics and Sustainable Development, 10(16), 162-174. https://doi.org/10.7176/JESD/1016-19

Snyder, H. (2019). Literature review as a research methodology: An overview and guidelines. Journal of Business Research, 104, 333-339. https://doi.org/10.1016/j.jbusres.2019.07.039

Suebpongsang P., Ekasingh, B., \& Cramb, R. (2020). Commercialisation of Rice Farming in Northeast Thailand. In: Cramb R. (Eds.), White Gold: The Commercialisation of Rice Farming in the Lower Mekong Basin (pp. 39-68). Palgrave Macmillan. https://doi.org/10.1007/978-981-15-0998-8_2

Tittonell, P. (2020). Assessing resilience and adaptability in agroecological transitions. $\begin{array}{lll}\text { Agricultural } & \text { Systems, } & 102862 .\end{array}$ https://doi.org/10.1016/j.agsy.2020.102862

Uday, P., \& Marais, K. (2014). Resilience-based system importance measures for systemof-systems. Procedia Computer Science, 28, 257-264. https://doi.org/10.1016/j.procs.2014.03.033

Van Oudenhoven, F., Mijatovic, D., \& Eyzaguirre, P. (2010). Social-ecological indicators of resilience in agrarian and natural landscapes. Management of Environmental Quality, 22(2), 154-173. https://doi.org/10.1108/14777831111113356

Wulandari, C. (2021). Identifying Climate Change Adaptation Efforts in the Batutegi Forest Management Unit, Indonesia. Forest and Society, 5(1), 48-59. https://doi.org/10.24259/fs.v5i1.73 